\title{
The application of nalbuphine in patient-controlled intravenous analgesia for patients undergoing subtotal gastrectomy
}

\author{
LI YANG $^{1 *}$, JINJING WU ${ }^{1 *}$ and TAO LI ${ }^{2}$ \\ ${ }^{1}$ Department of Anesthesiology, Xiangyang No. 1 People's Hospital, Hubei University of Medicine, \\ Xiangyang, Hubei 441000; ${ }^{2}$ Department of Anesthesiology, China-Japan Union Hospital \\ of Jilin University, Changchun, Jilin 130033, P.R. China
}

Received August 9, 2017; Accepted November 30, 2017

DOI: $10.3892 /$ etm. 2017.5632

\begin{abstract}
The aim of the present study was to investigate the analgesic effect and safety of the application of different doses of nalbuphine in patient-controlled intravenous analgesia (PCIA) for patients undergoing subtotal gastrectomy. A total of 120 patients, who underwent subtotal gastrectomy at our hospital between May, 2015 and January, 2017 under combined spinal epidural combined anesthesia, were selected. The patients received PCIA after surgery. The patients were randomly divided into four groups, including the morphine (MOP group), nalbuphine $60 \mathrm{mg}$ (N60 group), nalbuphine $80 \mathrm{mg}$ (N80 group) and nalbuphine $100 \mathrm{mg}$ (N100 group). The first dose of PCIA treatment was $2 \mathrm{ml}$, the background dose was $2 \mathrm{ml} / \mathrm{h}$, PCIA dose was $0.5 \mathrm{ml}$, and the lockout time was $15 \mathrm{~min}$. Postoperative vital signs and adverse reactions (bleeding, fullness and aching of upper abdomen and vomiting) were recorded. The visual analogue scale (VAS) and Ramsay sedation score of patients were evaluated. The number of PCIA and analgesia-related complications during analgesia were recorded. No significant differences in general data were found among the four groups $(\mathrm{P}>0.05)$. The VAS score of the three nalbuphine groups was lower than that of the MOP group, but the differences were not significant. All postoperative Ramsay sedation scores of the four groups showed appropriate sedation, but no significant differences were found between the groups. Compared with the MOP group, the use of postoperative PCIA was significantly delayed and the number of PCIA was significantly smaller in the three nalbuphine groups $(\mathrm{P}<0.05)$. The results show that the analgesic effect and safety of the use of PCIA for patients undergoing subtotal gastrectomy were satisfactory.
\end{abstract}

Correspondence to: Dr Tao Li, Department of Anesthesiology, China-Japan Union Hospital of Jilin University, 126 Xiantai Street, Changchun, Jilin 130033, P.R. China

E-mail: ib248u@163.com

${ }^{*}$ Contributed equally

Key words: subtotal gastrectomy, patient-controlled intravenous analgesia, nalbuphine, morphine

\section{Introduction}

The incidence of gastric cancer in recent years has been increasing, and surgical resection remains the main treatment (1). Pain is the main complication of surgical resection, and a series of chronic injuries occur without timely analgesia, which in turn delays postoperative recovery. Application of analgesic drugs is the main way to relieve pain after surgery. The most commonly used analgesic drugs, the opioid drugs, can act rapidly without the ceiling effect. Therefore, analgesic drugs are preferred in clinical practice (2). Currently known opioid receptors can be divided into $\mu, \delta, \kappa, \varepsilon$ and $\sigma(3)$. Commonly used opioid analgesic drugs mainly include fentanyl, sufentanil and morphine. These drugs achieve analgesic effect by exciting the central $\mu$ receptor. However, the application of those drugs can cause skin itching, nausea, vomiting, respiratory depression, urinary retention and other adverse reactions, which in turn negatively affect recovery and reduce a patient's satisfaction with surgery (4-6). $\kappa$ receptors have analgesic and sedative effects with distinct tolerance and addiction without cross-tolerance with $\mu$ receptor. The concentration of $\kappa$ receptor is high in the spinal cord; thus, the $\kappa$ receptor agonists induce only light respiratory depression with the ceiling effect. A $\kappa$ receptor agonist-antagonist, nalbuphine can agitate $\kappa$ receptor to achieve the analgesic effect, and antagonize the $\mu$ receptor to reduce the adverse effects (7). Thus, nalbuphine is a good postoperative analgesic drug, and a good antagonist of the adverse reactions caused by opioid drugs.

Different patients have varying pain tolerance and needs for analgesic medication. Patient-controlled intravenous analgesia (PCIA) is the most effective postoperative analgesia among all analgesic approaches currently used in clinical practice (8). With PCIA, patients may determine the dose of the analgesic drug themselves, which in turn, significantly improves patients' satisfaction. Drugs used in PCIA exert analgesic effects and adverse reactions. As the most commonly used PCIA drug, morphine may cause nausea, vomiting, dizziness, drowsiness and other adverse reactions, seriously affecting postoperative recovery and satisfaction with analgesia. Nalbuphine may be used to treat morphine-induced itching (9). In addition, apart from its application in adults, nalbuphine may also be used in pediatric surgery as a PCIA drug (10). 
In this study, patients undergoing subtotal gastrectomy were treated with PCIA using morphine and different doses of nalbuphine. Adverse effects caused by drugs were evaluated. The visual analogue scale (VAS) and Ramsay sedation scores were recorded. The analgesic effect and safety of nalbuphine and morphine were also compared.

\section{Materials and methods}

General information. A total of 120 patients were selected at the Xiangyang No. 1 People's Hospital, Hubei University of Medicine (Hubei, China) from May, 2015 and January, 2017. These patients included 76 males and 44 females, with an age range of 34 to 79 years and an average age of $57.4 \pm 13.6$ years. Of the 120 patients, 67 cases were diagnosed with gastric cancer, 30 cases with gastroduodenal ulcer bleeding, and 23 cases with gastric ulcer bleeding. Patients allergic to opioid drugs were excluded. Patients with severe coagulation dysfunction, liver and kidney dysfunction, and severe cardiopulmonary disease were also excluded.

Seventy-three patients received Billroth's I subtotal gastrectomy, 35 patients received Billroth's II subtotal gastrectomy, and 12 cases received gastrointestinal Roux-en-Y anastomosis. Patients were randomly divided into four groups $(n=40)$, including the morphine (MOP), nalbuphine $60 \mathrm{mg}$ (N60), nalbuphine $80 \mathrm{mg}$ (N80) and nalbuphine $100 \mathrm{mg}$ (N100) groups to receive PCIA with different drug doses.

The study was approved by the Ethics Committee of Xiangyang No. 1 People's Hospital. All the patients signed informed consent.

Surgery. The patients were required to learn how to use a self-controlled analgesic pump before surgery. Patients were fasted for $12 \mathrm{~h}$, and water deprivation was then performed for $8 \mathrm{~h}$. For the preoperative preparation, intravenous access was carried out, and the heart rate, blood pressure, ECG, peripheral capillary oxygen saturation $\left(\mathrm{SpO}_{2}\right)$, arterial partial pressure of carbon dioxide $\left(\mathrm{PaCO}_{2}\right)$ and urine volume were monitored. Venous transfusion, oxygen therapy and blood transfusion were performed. Combined spinal-epidural anesthesia was performed whereby epidural puncture was carried out on the region between spine $\mathrm{L} 2$ and $\mathrm{L} 3$, and $2 \mathrm{ml}$ of $0.5 \%$ bupivacaine was injected using lumbar anesthesia needle, followed by epidural catheterization. Billroth's I subtotal gastrectomy, Billroth's II subtotal gastrectomy and gastrointestinal Roux-en-Y anastomosis were performed. Following surgery, anesthetic infusion was stopped when closing the abdomen. After resuscitation, the analgesic pump was connected. Gastrointestinal decompression, nutritional support, anti-infection, fasting and other treatments were performed according to the patient's conditions. The gastric tube was removed after recovery of the gastrointestinal function. Patients were allowed to take liquid food, and then mashed food.

PCIA. The PCIA drugs were administered as follows: MOP group, morphine $5 \mu \mathrm{g} / \mathrm{kg}$ [(morphine hydrochloride injection, NEPHARM (Shenyang, China), FDA approval no. H20013351)]; nalbuphine groups (nalbuphlne hydrochloride; FDA approval no. H20130127; Yichang Humanwell Pharmaceutical Co., Ltd., Hubei, China), N60 group,
Table I. General information of the patient (mean \pm standard deviation).

\begin{tabular}{lccc}
\hline Items & $\begin{array}{c}\text { Age } \\
(\text { years })\end{array}$ & $\begin{array}{c}\text { Weight } \\
(\mathrm{kg})\end{array}$ & $\begin{array}{c}\text { Operation } \\
\text { time }(\mathrm{min})\end{array}$ \\
\hline MOP group $(\mathrm{n}=30)$ & $51.6 \pm 17.6$ & $57.5 \pm 9.6$ & $74.2 \pm 25.4$ \\
N60 group $(\mathrm{n}=30)$ & $53.1 \pm 15.7$ & $56.4 \pm 10.3$ & $69.7 \pm 23.3$ \\
N80 group $(\mathrm{n}=30)$ & $55.3 \pm 13.9$ & $59.6 \pm 12.5$ & $75.1 \pm 19.3$ \\
N100 group $(\mathrm{n}=30)$ & $52.7 \pm 14.2$ & $54.3 \pm 11.7$ & $71.7 \pm 27.6$ \\
F-value & 0.304 & 1.193 & 0.310 \\
P-value & 0.822 & 0.3169 & 0.818 \\
\hline
\end{tabular}

MOP, morphine.

nalbuphine $60 \mathrm{mg}$; N80 group, nalbuphine $80 \mathrm{mg}$; and N100 group, nalbuphine $100 \mathrm{mg}$. All the drugs were diluted in saline to a total volume of $100 \mathrm{ml}$. The first dose of PCIA treatment was $2 \mathrm{ml}$, the background dose was $2 \mathrm{ml} / \mathrm{h}$, PCIA dose was $0.5 \mathrm{ml}$, and the lockout time was $15 \mathrm{~min}$. Gemstar-7 infusion pump (Abbott Laboratories, Abbott Park, IL, USA) was used and $0.5 \mathrm{ml}$ of drugs were added each time, and the interval time for two additions was $\geq 10 \mathrm{~min}$. The patients recorded the time and number of PCIA use themselves.

Observation indicators. Postoperative vital signs and adverse reactions (bleeding, fullness and aching of upper abdomen and vomiting) at 1, 4, 8, 12, 24 and $48 \mathrm{~h}$ after operation were recorded. The time and number of the PCIA use were recorded. The VAS (11) and Ramsay sedation scores (12) were recorded. VAS was scored as $0-10$ points, where 0 points represented painless, 10 points represented most severe pain, $<3$ points were considered to be a satisfactory effect, 3-4 points were considered to be an accepted effect, and $>5$ points were considered to be a poor effect. The Ramsay sedation score was divided into six levels: restless, 1 point; patients were able to follow researchers, were calm and with directional force, 2 points; patients could respond to instructions, 3 points; patients were lethargic, but showed rapid response to stimulus of decibel sound, 4 points; patients were lethargic, and showed slow response to stimulus of decibel sound, 5 points; and patients were lethargic, and showed no response, 0 points. Assessment was performed by an individual blinded to the randomized grouping of the patients.

Statistical analysis. Statistical analysis was performed using SPSS 19.0 software (SPSS, Inc., Chicago, IL, USA). Measurement data were expressed as mean \pm standard deviation. ANOVA analysis was used for comparison between groups. Countable data were expressed as a percentage (\%), and comparison of groups was performed using the Chi-square test, Kruskal-Wallis test and Fisher's exact probability method. $\mathrm{P}<0.05$ was considered statistically significant.

\section{Results}

General information of the patient. General information including age, weight and duration of operation are shown 
Table II. Postoperative VAS scores of the four groups of patients.

\begin{tabular}{|c|c|c|c|c|c|c|}
\hline Items & $1 \mathrm{~h}$ & $4 \mathrm{~h}$ & $8 \mathrm{~h}$ & $12 \mathrm{~h}$ & $24 \mathrm{~h}$ & $48 \mathrm{~h}$ \\
\hline MOP group & $0.75 \pm 0.52$ & $1.56 \pm 0.73$ & $2.16 \pm 1.21^{\mathrm{a}}$ & $1.93 \pm 0.96$ & $1.35 \pm 0.65$ & $0.94 \pm 0.65$ \\
\hline N60 group & $0.67 \pm 0.47$ & $1.25 \pm 0.91$ & $1.94 \pm 1.13$ & $1.83 \pm 0.87$ & $1.27 \pm 0.92$ & $0.89 \pm 0.42$ \\
\hline N80 group & $0.57 \pm 0.44$ & $1.19 \pm 0.84$ & $1.85 \pm 0.72$ & $1.76 \pm 1.15$ & $1.21 \pm 0.84$ & $0.78 \pm 0.51$ \\
\hline N100 group & $0.40 \pm 0.51$ & $1.27 \pm 0.75$ & $1.97 \pm 0.85$ & $1.86 \pm 1.03$ & $1.23 \pm 0.78$ & $0.83 \pm 0.54$ \\
\hline F-value & 2.730 & 1.246 & 1.537 & 0.147 & 0.178 & 0.508 \\
\hline P-value & 0.047 & 0.296 & 0.209 & 0.932 & 0.911 & 0.678 \\
\hline
\end{tabular}

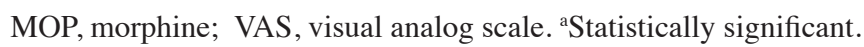

Table III. Postoperative Ramsay sedation scores of the four groups of patients.

\begin{tabular}{|c|c|c|c|c|c|c|}
\hline Items & $1 \mathrm{~h}$ & $4 \mathrm{~h}$ & $8 \mathrm{~h}$ & $12 \mathrm{~h}$ & $24 \mathrm{~h}$ & $48 \mathrm{~h}$ \\
\hline MOP group & $2.54 \pm 0.73$ & $2.38 \pm 0.65$ & $2.31 \pm 0.58$ & $2.27 \pm 0.49$ & $1.76 \pm 0.67$ & $1.21 \pm 0.34$ \\
\hline N60 group & $2.38 \pm 0.81$ & $2.32 \pm 0.69$ & $2.28 \pm 0.53$ & $2.15 \pm 0.43$ & $1.57 \pm 0.52$ & $0.97 \pm 0.46$ \\
\hline N80 group & $2.29 \pm 0.65$ & $2.25 \pm 0.57$ & $2.17 \pm 0.45$ & $2.05 \pm 0.38$ & $1.59 \pm 0.43$ & $1.03 \pm 0.31$ \\
\hline N100 group & $2.17 \pm 0.54$ & $2.11 \pm 0.65$ & $2.03 \pm 0.48$ & $1.95 \pm 0.52$ & $1.48 \pm 0.39$ & $0.87 \pm 0.35$ \\
\hline F-value & 1.532 & 0.823 & 1.839 & 2.682 & 1.553 & 4.485 \\
\hline P-value & 0.210 & 0.484 & 0.144 & 0.050 & 0.205 & 0.005 \\
\hline
\end{tabular}

MOP, morphine.

Table IV. Postoperative complications and adverse reactions.

\begin{tabular}{lcccc}
\hline Variables & MOP & N60 & N80 & N100 \\
\hline Postoperative complications & & & & \\
$\quad$ Anastomotic fistula & 2 & 1 & 2 & 1 \\
Delayed gastric emptying & 1 & 2 & 1 & 1 \\
Incision infection & 2 & 3 & 1 & 2 \\
Gastric hemorrhage & 2 & 2 & 2 & 0 \\
Total & 7 & 8 & 6 & 4 \\
Postoperative adverse reactions & & & & \\
$\quad$ Skin itching & 1 & 1 & 0 & 1 \\
Nausea and vomiting & 2 & 1 & 1 & 1 \\
Urinary retention & 1 & 1 & 0 & 0 \\
Total & 4 & 3 & 1 & 2 \\
\hline
\end{tabular}

MOP, morphine.

in Table I. No significant differences in the general data (age, weight) and operation time were found among the four groups of patients $(\mathrm{P}>0.05)$.

Postoperative observation indicators. The VAS score of the four groups increased gradually from 1 to $8 \mathrm{~h}$ after surgery, and the peak was reached at $8 \mathrm{~h}$, followed by a decrease. The VAS score of the three nalbuphine groups was significantly lower than that of the MOP group at $1 \mathrm{~h}$ after operation, indicating that the analgesic effect of nalbuphine was superior than that of morphine. However, no significant differences in

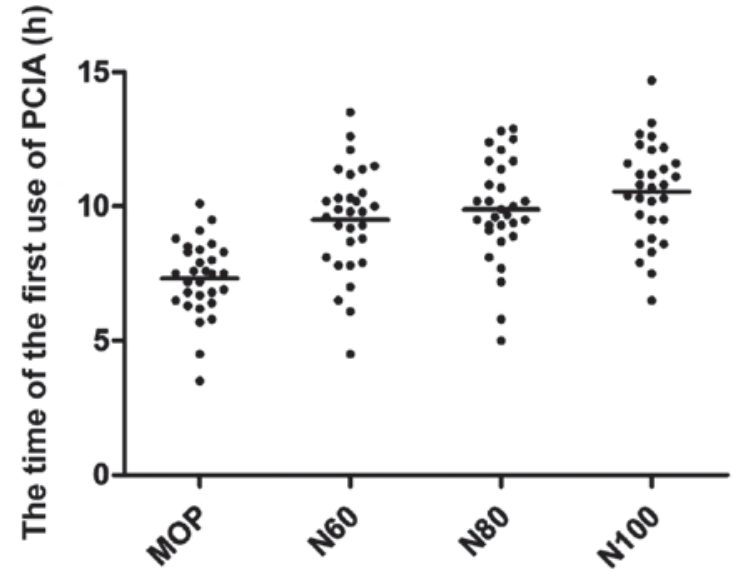

Figure 1. The time of the first use of patient-controlled intravenous analgesia (PCIA). PCIA was performed by patients themselves after surgery using analgesic pump. morphine $5 \mu \mathrm{g} / \mathrm{kg}$, nalbuphine $60 \mathrm{mg}$, nalbuphine $80 \mathrm{mg}$, nalbuphine $100 \mathrm{mg}$. The time of the first use of PCIA was recorded.

the analgesic effect were found among the four groups from 1 to $48 \mathrm{~h}$ after operation ( $\mathrm{P}>0.05$ ) (Table II).

The Ramsay sedation score of the four groups gradually decreased from 1 to $12 \mathrm{~h}$ after operation. The decrease became more significant from 24 to $48 \mathrm{~h}$ after operation, indicating the revival of anesthesia at $24 \mathrm{~h}$ after operation. The Ramsay scores of the three nalbuphine groups were lower than that of the MOP group from 1 to $48 \mathrm{~h}$ after operation, but significant difference was only found at $48 \mathrm{~h}(\mathrm{P}<0.01)$, indicating the analgesic effect of nalbuphine was superior than that of morphine at $48 \mathrm{~h}$ after operation (Table III). 
Time and number of the use of PCIA. Patients received PCIA after surgery. The average time of the first use of PCIA was significantly longer in the three nalbuphine groups than in the MOP group $(\mathrm{P}<0.05)$, indicating the lower degree of pain of patients in the nalbuphine groups than in the MOP group. No significant differences in the average time of the first use of PCIA were found among the three nalbuphine groups (Fig. 1). The average number of the use of PCIA in MOP, N60, N80 and N100 groups were 5.3 $\pm 2.1,3.8 \pm 2.6,3.2 \pm 1.7$ and $2.9 \pm 1.5$, respectively. The number of the use of PCIA was larger in the MOP group than in the nalbuphine groups $(\mathrm{P}<0.05)$. In the three nalbuphine groups, the use of PCIA decreased along with the increase of the dose of nalbuphine.

Postoperative complications and adverse reactions. The patients were treated with gastric tube and nasal nutrition tube, and abdominal drainage tube was used for 32 cases. Postoperative complications were found in 25 cases, including anastomotic fistula in 6 cases, delayed gastric emptying in 5 cases, incision infection in 8 cases, and gastric hemorrhage in 6 cases. No significant differences in the incidence of postoperative complications were found among the groups $\left(\chi^{2}=1.7684, \mathrm{P}=0.6218\right)$.

Adverse reactions included 3 cases of skin itching (1 case in the MOP group, 1 case in the N60 group, and 1 case in the N100 group), 5 cases of nausea and vomiting (2 cases in the MOP group, 1 case in the N60 group, 1 case in the N80 group, and 1 case in the N100 group), and 2 cases of urinary retention (1 case in the MOP group, and 1 case in the N60 group). Respiratory depression or dizziness was not found in patients. No significant differences in the incidence of postoperative complications were found between the nalbuphine groups and the MOP group. All the patients recovered after proper treatment. Calculation using Fisher's exact probability method showed $\mathrm{P}=0.6918$, indicating that there was no significant difference in the incidence of postoperative adverse reactions among the groups (Table IV).

\section{Discussion}

Postoperative analgesia is extremely important after surgery. Opioid drugs are the most widely used analgesic drugs with good effects, but they can cause adverse reactions including nausea, vomiting and urinary retention, which in turn affect postoperative rehabilitation (13). As a novel opioid $\kappa$ receptor agonist-antagonist, nalbuphine can agitate the $\kappa$ receptor to achieve an analgesic effect, and antagonize the $\mu$ receptor to reduce the incidence of adverse reactions. The half-life of nalbuphine in blood was $2.3 \mathrm{~h}$, which was longer than that of morphine $(1.7 \mathrm{~h})$. Effective concentration may be reached after sustained infusion of nalbuphine to produce a sustained analgesic effect (14). In this study, the VAS scores of the nalbuphine groups was lower than that of the MOP group, and the time of the first use of PCIA was longer than that of MOP group, indicating the analgesic effects of nalbuphine were superior to morphine, but did not achieve significant differences. Results of this study and previous studies showed better analgesic effects compared with morphine $(15,16)$. Postoperative complications included anastomotic fistula in 6 cases, delayed gastric emptying in 5 cases, incision infection in 8 cases, and gastric hemorrhage in 6 cases. Adverse reactions included skin itching in 3 cases, nausea and vomiting in 5 cases, and urinary retention in 2 cases. Respiratory depression or dizziness was not observed in patients. Consistent with previous findings, nalbuphine as a PCIA drug has no significant difference in safety compared with morphine (15).

In conclusion, nalbuphine as a PCIA drug in subtotal gastrectomy can achieve satisfactory analgesic effect. Compared with morphine, the incidence of adverse reactions was reduced, indicating superior safety.

\section{References}

1. Santoro R, Ettorre GM and Santoro E: Subtotal gastrectomy for gastric cancer. World J Gastroenterol 20: 13667-13680, 2014.

2. Chou R, Fanciullo GJ, Fine PG, Adler JA, Ballantyne JC, Davies P, Donovan MI, Fishbain DA, Foley KM, Fudin J, et al; American Pain Society-American Academy of Pain Medicine Opioids Guidelines Panel: Clinical guidelines for the use of chronic opioid therapy in chronic noncancer pain. J Pain 10: 113-130, 2009

3. Stein C: Opioid receptors. Annu Rev Med 67: 433-451, 2016.

4. Vadivelu N, Mitra S and Hines RL: Peripheral opioid receptor agonists for analgesia: A comprehensive review. J Opioid Manag 7: 55-68, 2011.

5. Kjellberg F and Tramèr MR: Pharmacological control of opioid-induced pruritus: A quantitative systematic review of randomized trials. Eur J Anaesthesiol 18: 346-357, 2001.

6. Vučković SM, Savić Vujović KR, Srebro DP, Medić BM, Stojanović RM, Vučetić CS, Divac N and Prostran MS: The antinociceptive efficacy of morphine-ketamine-magnesium combination is influenced by the order of medication administration. Eur Rev Med Pharmacol Sci 19: 3286-3294, 2015.

7. Gunion MW, Marchionne AM and Anderson CTM: Use of the mixed agonist-antagonist nalbuphine in opioid based analgesia. Acute Pain 6: 29-39, 2004.

8. Brown AK, Christo PJ and Wu CL: Strategies for postoperative pain management. Best Pract Res Clin Anaesthesiol 18: 703-717, 2004.

9. Jannuzzi RG: Nalbuphine for treatment of opioid-induced pruritus: A systematic review of literature. Clin J Pain 32: 87-93, 2016.

10. Schnabel A, Reichl SU,Zahn PK and Pogatzki-Zahn E: Nalbuphine for postoperative pain treatment in children. Cochrane Database Syst Rev: Jul 31, 2014 (Epub ahead of print). doi: 10.1002/14651858. CD009583.pub2.

11. Jensen MP, Chen C and Brugger AM: Postsurgical pain outcome assessment. Pain 99: 101-109, 2002.

12. Sessler CN, Grap MJ and Ramsay MA: Evaluating and monitoring analgesia and sedation in the intensive care unit. Crit Care 12 (Suppl 3): S2, 2008.

13. Argoff CE and Viscusi ER: The use of opioid analgesics for chronic pain: Minimizing the risk for harm. Am J Gastroenterol Suppl 2: 3-8, 2014.

14. Zeng Z, Lu J, Shu C, Chen Y, Guo T, Wu QP, Yao SL and Yin P: A comparision of nalbuphine with morphine for analgesic effects and safety: Meta-analysis of randomized controlled trials. Sci Rep 5: 10927, 2015.

15. Minai FN and Khan FA: A comparison of morphine and nalbuphine for intraoperative and postoperative analgesia. J Pak Med Assoc 53: 391-396, 2003.

16. Akshat S, Ramachandran R, Rewari V, Chandralekha, Trikha A and Sinha R: Morphine versus nalbuphine for open gynaecological surgery: A randomized controlled double blinded trial. Pain Res Treat 2014: 727952, 2014. International (CC BY-NC-ND 4.0) License. 